\title{
Persepsi Mahasiswa Profesi Kesehatan Universitas Padjadjaran terhadap Interprofessionalism Education
}

\author{
Assica Permata Amalya Hakiman, ${ }^{1}$ Sari Puspa Dewi, ${ }^{2}$ Chevi Sayusman, ${ }^{3}$ Kurnia Wahyudi. ${ }^{4}$ \\ ${ }^{1}$ Program Studi Sarjana, Kedokteran Fakultas Kedokteran, Universitas Padjadjaran \\ ${ }^{2}$ Departmen Ilmu Kesehatan Masyarakat, Fakultas Kedokteran, Universitas Padjadjaran \\ ${ }^{3}$ Departemen Ilmu Kedokteran Forensik dan Medikolegal, Fakultas Kedokteran, Universitas Padjadjaran/Rumah \\ Sakit Umum Pendidikan Hasan Sadikin \\ ${ }^{4}$ Departemen Epidemiologi dan Biostatistika, Fakultas Kedokteran, Universitas Padjadjaran
}

\begin{abstract}
Abstrak
Interprofessional Collaboration (IPC) yang buruk menjadi faktor penting dalam kesalahan medis. IPC dapat ditingkatkan sejak masa pendidikan melalui Interprofessionalism Education (IPE). Penelitian ini bertujuan untuk mengetahui persepsi mahasiswa program studi rumpun ilmu kesehatan Universitas Padjadjaran (Unpad) terhadap IPE. Metode penelitian analitik komparatif menggunakan kuesioner Interdisciplinary Education Perception Scale (IEPS) yang diterjemahkan dan divalidasi dibagikan kepada mahasiswa Program Studi Kedokteran, Pendidikan Kedokteran Gigi, Farmasi, Keperawatan, Diploma Kebidanan, serta Profesi Dokter, Dokter Gigi, Apoteker, dan Ners Unpad sejumlah 252 mahasiswa meliputi 28 mahasiswa dari setiap program studi. Persepsi mahasiswa dikategorikan menjadi baik, cukup baik, dan kurang baik. Uji t independen dilakukan untuk membandingkan kelompok sarjana dan diploma dengan profesi, sedangkan One way Anova dan Post Hoc Tukey digunakan untuk membandingkan antar program studi pada kelompok sarjana dan diploma serta profesi.Hasil Persepsi 98\% responden masuk ke dalam kategori baik. Uji Anova menunjukkan perbedaan signifikan antar program studi pada kelompok sarjana dan diploma $(p=0,004)$ serta pada kelompok profesi $(p<0,001)$. Komponen IPE "Kebutuhan yang dirasakan untuk kerjasama profesional" memiliki persepsi baik yang lebih rendah dibandingkan dengan komponen "Kompetensi dan otonomi" dan "Persepsi kerjasama aktual". Diskusi Mahasiswa sudah memahami mengenai peran dan kompetensi masing-masing profesi. Namun, pemahaman mengenai profesi tenaga kesehatan lain dan pentingnya kerjasama antar profesi masih kurang, sehingga perlu diadakan IPE di Unpad.
\end{abstract}

Kata Kunci: Interprofessional collaboration, interprofessional education, mahasiswa, persepsi

\section{Perception of Health Profession Students of Universitas Padjadjaran on Interprofessionalism Education}

\begin{abstract}
Poor Interprofessional Collaboration (IPC) is an important factor in medical errors. IPC can be improved through Interprofessionalism Education (IPE). This study aimed to determine perceptions of health profession students of Universitas Padjadjaran (Unpad) on IPE. Methods Comparative analytic study was carried out using translated and validated Interdisciplinary Education Perception Scale (IEPS) questionnaire and distributed to students in various major: Medicine, Dentistry, Pharmacy, Nursing, Midwifery, Doctor Profession, Dentist Profession, Professional Pharmacy, and Professional Nurses in Unpad. 252 respondents were enrolled in this study included 28 students from each program. Student's perceptions were categorized as good, fair, and poor. Independent t test was conducted to compare undergraduate and diploma with profession groups, while One way Anova and Post Hoc Tukey used to find significant differences between major at undergraduate and diploma as well as the professional groups. Results Perceptions of $98 \%$ respondent's were categorized as good. Anova test results revealed significant difference between majors in undergraduate groups $(p=0,004)$, as well as professional groups $(p<0,001)$. The good perception on components of "perceived need for professional cooperation" is lower than the components of "competence and autonomy" and components of "perception of actual co-operation". Discussion Students have understood the role and competence of each profession. However, an understanding of the profession of other health professionals and the importance of cooperation among the profession is still lacking, so IPE needs to be held at Unpad.
\end{abstract}

Keywords: Interprofessional collaboration, interprofessional education, perception, student

Korespondensi:

Assica Permata Amalya Hakiman

Program Studi Sarjana, Kedokteran Fakultas Kedokteran, Universitas Padjadjaran

Jl. Prof. Dr. Eyckman No. 38 Bandung 40161

Mobile : 082112877360

Email : assicapermata@live.com 


\section{Pendahuluan}

Menurut Joint Commission on Accreditation of Healthcare Organizations, kesalahan medis menempati peringkat kelima dalam sepuluh penyebab kematian paling banyak di Amerika Serikat. Akar dari permasalahan tersebut adalah buruknya kolaborasi antar tenaga kesehatan yang menyebabkan keterlambatan pengobatan serta kesalahan fatal pada operasi. ${ }^{1}$ Di Indonesia, pada 98,69\% pembuatan resep terdapat kesalahan yang meliputi kesalahan dalam penulisan resep oleh dokter, apoteker yang tidak tepat dalam proses penyiapan obat, dan kesalahan pada saat pemberian informasi mengenai obat tersebut. ${ }^{2}$ National Prescribing Service Australia menemukan bahwa 6\% kasus di rumah sakit disebabkan karena efek samping obat dan tingkat kesalahan yang tinggi selama pemindahan perawatan. Sumber dari masalah tersebut adalah kolaborasi yang buruk antara dokter dan apoteker. Masalah ini menjadi contoh kolaborasi yang buruk antar tenaga kesehatan. Kolaborasi yang buruk adalah faktor yang paling penting dalam kesalahan medikasi dan pengobatan., ${ }^{1,2}$ Pada praktik kolaborasi antar tenaga kesehatan sering terjadi masalah seperti ketidakseimbangan wewenang, peran yang tumpang tindih, serta struktur organisasi. Masalah tersebut seharusnya bisa diselesaikan dengan implementasi dari komponen praktik kolaborasi yang baik. ${ }^{3,4}$

Praktik kolaborasi yang baik di antara profesi rumpun ilmu kesehatan dikenal dengan Interprofessional Collaboration (IPC). Karena dapat lebih mensinergiskan dan mengefektifkan perawatan yang diberikan kepada pasien, IPC merupakan hal yang penting. ${ }^{5}$ Keberlangsungan IPC akan lebih baik apabila seluruh tenaga kesehatan memahami peran, kompetensi inti, dasar bahasa dan pola pikir dari tenaga kesehatan lain serta mengembangkan sikap dan perilaku yang baik. ${ }^{6}$

Peningkatakan IPC dapat dilakukan dengan mengenalkan profesi lain dan sistem kolaborasi sejak masa pendidikan melalui Interprofessionalism Education (IPE). Definisi IPE adalah "setiap bentuk pendidikan, pelatihan pengajaran ataupun pembelajaran yang terdapat dua atau lebih profesi tenaga kesehatan dan sosial yang melakukan pembelajaran secara interaktif'. WHO telah mendukung IPE karena dianggap sebagai langkah penting dalam meningkatkan pendidikan profesi kesehatan. Pada tahun 2013, WHO mengeluarkan Framework for Action on Interprofessional Education and Collaboration Practice sebagai bentuk dukungan terhadap IPE. Program IPE dinilai dapat meningkatkan kualitas pelayanan kesehatan secara keseluruhan, sehingga diharapkan dapat meningkatkan pelayanan kesehatan kepada pasien. ${ }^{6,8,9}$

Di Indonesia, IPE sudah dijadikan sebagai bagian dari kurikulum sehari-hari, seperti di Universitas Indonesia (UI), Universitas Gadjah Mada (UGM), Universitas Muhammadiyah Yogyakarta (UMY), dan Universitas Islam Indonesia (UII). Di Fakultas Kedokteran dan Ilmu Kesehatan (FKIK) UMY, 4-6 mahasiswa dari empat program studi yang berbeda melakukan diskusi bersama setiap hari minggu. Sebuah penelitian menunjukkan bahwa mahasiswa FKIK UMY tahap profesi memiliki persepsi yang baik terhadap IPE. ${ }^{10}$ Penelitian lain menunjukkan bahwa $97,21 \%$ mahasiswa FKIK Universitas Islam Negeri (UIN) Syarif Hidayatullah Jakarta yang terdiri dari Program Studi Ilmu Keperawatan, Farmasi, Kesehatan Masyarakat, dan Kedokteran mempunyai persepsi baik terhadap IPE. ${ }^{11}$ Di Universitas Padjadjaran (Unpad), IPE baru dijalankan di masing-masing program studi sebagai sebuah intrakurikulum, akan tetapi tidak ada pelaksanaan IPE antar program studi.

Beberapa faktor yang memengaruhi pembentukan kolaborasi dan efektivitasnya adalah persepsi dan pemahaman mengenai profesi tenaga kesehatannya masing-masing dan profesi tenaga kesehatan lain. ${ }^{12}$ Oleh karena itu, penelitian ini bertujuan untuk membandingkan persepsi mahasiswa antar program studi rumpun ilmu kesehatan Unpad mengenai IPE sehingga kesiapan mahasiswa terhadap IPE dapat tergambarkan.

\section{Metode}

Penelitian ini merupakan penelitian analitik komparatif menggunakan data primer dari hasil kuesioner di Unpad pada bulan September sampai dengan Desember 2015. Penelitian ini telah mendapatkan izin dari Komite Etik Penelitian Kesehatan - Fakultas Kedokteran Universitas Padjadjaran dengan nomor surat 536/UN6. C1.3.2/KEPK/PN/2015.

Subjek penelitian merupakan mahasiswa program studi rumpun ilmu kesehatan Unpad yaitu mahasiswa Program Studi Kedokteran, Pendidikan Kedokteran Gigi, Farmasi, Keperawatan, Diploma Kebidanan, Profesi Dokter (PSPD), Profesi Dokter Gigi (PSPDG), Profesi Apoteker (Apoteker), dan Profesi Ners (Ners) yang terdaftar sebagai mahasiswa aktif tahun akademik 2015/2016. Kriteria inklusinya adalah mahasiswa program studi profesi tahun pertama atau mahasiswa program studi sarjana dan diploma tahun ketiga serta berkewarganegaraan Indonesia. Mahasiswa program kelas internasional, mahasiswa program 
studi profesi yang sedang berada di rumah sakit jejaring, dan mahasiswa program studi sarjana dan diploma yang tidak sedang berada di Jatinangor karena mengikuti Kuliah Kerja Nyata, kerja lapangan, ataupun kegiatan perkuliahan luar lainnya, tidak diikutsertakan dalam penelitian ini. Perhitungan besar sampel diibantu dengan piranti lunak $G^{*}$ Power versi 3.1.9.2 untuk sistem operasi Windows. ${ }^{13,14}$ Besar $\alpha, \beta$, dan Cohen effect size untuk ANOVA ditentukan sebesar 0,05, 0,2, dan 0,25 secara berturut-turut. Untuk kelompok berjumlah 9, maka diperlukan n total sebesar 252 responden meliputi 28 orang dari setiap kelompok yang dipilih secara acak. Sampel dipilih dengan menggunakan metode pengambilan stratifikasi disproporsional.

Instrumen yang digunakan adalah kuesioner Interdisciplinary Education Perception Scale (IEPS) yang dikembangkan oleh Luecht dkk pada tahun 1990. Kuesioner IEPS kemudian dimodifikasi oleh McFadyen pada tahun 2007 dengan menghilangkan beberapa poin pertanyaan yang tidak dapat diterapkan kepada mahasiswa yang belum menjalani fase klinik sehingga validitasnya lebih baik. ${ }^{13}$ Kuesoner IEPS digunakan karena dapat mengukur persepsi mengenai IPE dan komponennya. Kuesioner IEPS mengukur tiga aspek sikap yang penting di dalam interdisipliner, yaitu Kompetensi dan Otonomi (butir 1, 3, 5, 7, 8); Kebutuhan yang dirasakan untuk kerjasama profesional (butir 4 dan 6); Persepsi kerjasama dan pembagian sumber daya intra dan inter profesi (butir 2, 9, 10 , 11, 12).

Ketiga faktor ini digambarkan dalam 12 pertanyaan. Penilaian dilakukan dengan menggunakan skala Likert, yaitu terdapat nilai 1-6 pada setiap pertanyaan. Setiap butir pertanyaan nilai yang diperoleh adalah; $6=$ sangat setuju, $5=$ setuju, $4=$ agak setuju, $3=$ agak tidak setuju, $2=$ tidak setuju, 1 = sangat tidak setuju.

Jawaban setiap responden dijumlahkan menjadi total nilai dan dikonversi dengan skala nilai akhir 12 sampai dengan 72 serta dikategorikan berdasarkan teori Saifuddin Azwar ${ }^{14}$ dilihat dari tabel 1.

Kuesioner IEPS yang sudah diterjemahkan ke dalam bahasa Indonesia dan divalidasi, kemudian diisi oleh mahasiswa setelah diberikan penjelasan mengenai tujuan penelitian, tata cara pengisian kuesioner, serta kerahasiaan data. Data yang tidak lengkap dieksklusi dari penelitian. Penelitian ini menggunakan selang kepercayaan sebesar 95\% dan hasilnya dikatakan signifikan apabila nilai $\mathrm{p}<$ 0,05 . Penelitian ini menggunakan dua uji statistik, yaitu uji t independen dan one way Anova untuk mencari perbedaan signifikan pada persepsi responden mengenai IPE secara keseluruhan, sedangkan pada persepsi responden untuk setiap komponen tidak dilakukan uji statistik. Uji $t$ independen digunakan untuk membandingkan kelompok sarjana dan diploma dengan profesi. Normalitas data diuji menggunakan uji ShapiroWilk karena jumlah subjek dalam setiap kelompok $\leq 50$. Homogenitas data diuji dengan uji Levene. Apabila uji Shapiro-Wilk dan uji Levene memberikan nilai signifikansi $>0,05$, maka one way Anova dilakukan untuk mengetahui apakah terdapat perbedaan yang signifikan antar kelompok. Apabila data tidak terdistribusi normal dan variansinya tidak homogen, maka dilakukan uji non parametrik Kruskal Wallis. Karena data terdistribusi normal dengan nilai dan variansinya homogen, maka dilakukan uji $\mathrm{t}$ independen dan one way Anova. Hasil kuesioner dalam bentuk data deskriptif (persentase dan jumlah) dipresentasikan dalam bentuk tabel.

\section{Hasil}

Sebanyak 83,7\% responden berjenis kelamin perempuan. Untuk program studi sarjana dan diploma, rerata usia responden adalah 19,98 dengan simpangan baku (SB) 0,63, sedangkan pada program studi profesi, rerata usia responden (SB) adalah 21,88 $(0,73)$

Mayoritas pendidikan terakhir responden dari

Tabel 1 Klasifikasi Nilai Komponen IPE

\begin{tabular}{llccc}
\hline \multirow{2}{*}{ No } & \multicolumn{1}{c}{ Komponen IPE } & \multicolumn{3}{c}{ Klasifikasi Nilai } \\
\cline { 3 - 5 } & & Baik & Cikup Baik & Kurang Baik \\
\hline 1 & Nilai total seluruh komponen IPE & $>52$ & $32-51$ & $<32$ \\
2 & $\begin{array}{l}\text { Kompetensi dan otonomi (butir 1, 3, 5, 7, 8) } \\
3\end{array}$ & $\geq 21,6$ & $13,4-21,5$ & $<13,4$ \\
& $\begin{array}{l}\text { Kebutuhan yang dirasakan untuk kerjasama } \\
\text { profesional (butir 4 dan 6) }\end{array}$ & $\geq 8$ & $6-7$ & $<6$ \\
4 & $\begin{array}{l}\text { Persepsi Kerjasama Aktual (butir 2, 9, 10, } \\
\text { 11, 12) }\end{array}$ & $\geq 21,6$ & $13,4-21,5$ & $<13,4$ \\
\hline
\end{tabular}


program studi sarjana adalah Sekolah Menengah Atas (97,1\%). Pada program studi profesi, seluruh responden menyelesaikan pendidikan sarjana di Unpad kecuali pada Apoteker, terdapat 42,9\% responden yang menyelesaikan pendidikan sarjana di universitas lain. Data terdistribusi normal sehingga dilakukan penghitungan rerata dan simpangan baku. Sebagian besar responden, yaitu sebanyak 98\% memiliki persepsi baik terhadap IPE dengan rerata dan simpangan baku sebesar 61,4 dan 4,5.

Hasil uji $t$ independen pada perbandingan kelompok sarjana dan diploma dengan profesi tidak menemukan perbedaan signifikan (nilai $\mathrm{p}$ $=0,288)$. Akan tetapi, uji Anova menunjukkan perbedaan yang signifikan antar kelompok sarjana dan diploma dengan nilai $p=0,004$. Uji Post Hoc Tukey menemukan bahwa Program Studi Diploma Kebidanan memiliki perbedaan signifikan dengan Program Studi Kedokteran (adjusted- $p=0,031$ ), Program Studi Pendidikan Kedokteran Gigi (adjusted- $p=0,025$ ) dan Program Studi Farmasi (adjusted- $p=0,021$ ).

Pada kelompok profesi, hasil uji Anova menunjukkan perbedaan yang signifikan antar kelompok profesi dengan nilai $\mathrm{p}<0,001$. Melalui uji Post Hoc Tukey didapatkan bahwa Program Studi Profesi Apoteker memiliki perbedaan signifikan dengan Program Studi Profesi Dokter (adjusted- $p=0,002$ ) dan Program Studi Profesi Ners (adjusted- $p=0,001$ ).

Jumlah responden yang memiliki persepsi baik pada komponen "kebutuhan yang dirasakan untuk kerjasama profesional" $(86,9 \%)$ lebih sedikit dibandingkan dengan komponen "kompetensi dan otonomi" (96,8\%) serta komponen "persepsi kerjasama Aktual" (98,8\%). Bahkan, terdapat responden yang memiliki persepsi kurang baik pada komponen "kebutuhan yang dirasakan untuk kerjasama profesional", sedangkan pada dua komponen lainnya tidak ada. Hal ini menunjukkan bahwa pemahaman mahasiswa mengenai komponen "kebutuhan yang dirasakan untuk kerjasama profesional" lebih rendah dibandingkan dengan dua komponen lainnya.

\section{Pembahasan}

Sebagian besar responden, yaitu sebanyak 98\% memiliki persepsi baik terhadap IPE. Mahasiswa program studi sarjana dan diploma memiliki persepsi yang lebih baik dibandingkan dengan mahasiswa program studi profesi. Keseluruhan responden program studi sarjana dan diploma memiliki persepsi baik. Namun,

Tabel 2 Persepsi Mahasiswa Rumpun Ilmu Kesehatan Unpad terhadap IPE

\begin{tabular}{llcccc}
\hline No & \multicolumn{1}{c}{ Program Studi } & Rerata Nilai (SB) & \multicolumn{3}{c}{ Persepsi (\%) } \\
\cline { 3 - 5 } & & & Baik & Cukup Baik & Kurang Baik \\
\hline 1 & Kedokteran & $60,7(3,6)$ & $28(100 \%)$ & $0(0 \%)$ & $0(0 \%)$ \\
2 & Pendidikan Kedokteran Gigi & $60,6(5,1)$ & $28(100 \%)$ & $0(0 \%)$ & $0(0 \%)$ \\
3 & Keperawatan & $62,9(3,6)$ & $28(100 \%)$ & $0(0 \%)$ & $0(0 \%)$ \\
4 & Farmasi & $60,5(3,3)$ & $28(100 \%)$ & $0(0 \%)$ & $0(0 \%)$ \\
5 & Diploma Kebidanan & $63,9(4,7)$ & $28(100 \%)$ & $0(0 \%)$ & $0(0 \%)$ \\
6 & Profesi Dokter & $59,6(3,8)$ & $27(96,4 \%)$ & $1(3,6 \%)$ & $0(0 \%)$ \\
7 & Profesi Dokter Gigi & $61,4(4)$ & $27(96,4 \%)$ & $1(3,6 \%)$ & $0(0 \%)$ \\
8 & Profesi Ners & $59,4(4,8)$ & $25(89,3 \%)$ & $3(10,7 \%)$ & $0(0 \%)$ \\
9 & Profesi Apoteker & $64(5,2)$ & $28(100 \%)$ & $0(0 \%)$ & $0(0 \%)$ \\
& Total & $61,4(4,5)$ & $247(98 \%)$ & $5(2 \%)$ & $0(0 \%)$ \\
\hline
\end{tabular}

Tabel 3 Perbandingan nilai P antar Kelompok Sarjana dan Diploma dengan Profesi

\begin{tabular}{lcccc}
\hline \multicolumn{1}{c}{ Kelompok } & n & Rerata $($ SB $)$ & Selisih $(\mathbf{I K}=\mathbf{9 5 \%}$ ) & Nilai P \\
\hline Sarjana dan Diploma & 140 & $61,73(4,29)$ & $-0,61(-1,74 \%, 0,52)$ & 0,288 \\
Profesi & 112 & $61,12(4,78)$ & & \\
\hline
\end{tabular}

Jjit independen 
Tabel 4 Perbandingan nilai P antar Program Studi pada Kelompok Sarjana dan Diploma

\begin{tabular}{llllll}
\hline & Kedokteran & $\begin{array}{l}\text { P e n d i d i k a n } \\
\text { Kedokteran Gigi }\end{array}$ & Keperawatan & Farmasi & Diploma Kebidanan \\
\hline Kedokteran & & 1,000 & 0,268 & 1,000 & $0,031^{*}$ \\
$\begin{array}{l}\text { Pendidikan } \\
\text { Kedokteran Gigi }\end{array}$ & - & & 0,238 & 1,000 & $0,025^{*}$ \\
Keperawatan & - & - & & 0,211 & 0,811 \\
Farmasi & - & - & - & & $0,021^{*}$ \\
$\begin{array}{l}\text { Diploma } \\
\text { Kebidanan }\end{array}$ & - & - & - & - & \\
Uji statistik menggunakan one way ANOVA dan Post Hoc Tukey \\
$*$ terdapat perbedaan signifikan. Nilai $\mathrm{p}<0,05$
\end{tabular}

Tabel 5 Perbandingan nilai P antar Program Studi pada Kelompok Profesi

\begin{tabular}{lcccc}
\hline & Profesi Dokter & Profesi Dokter Gigi & Profesi Ners & Profesi Apoteker \\
\hline Profesi Dokter & & 0,410 & 0,999 & $0,002 *$ \\
Profesi Dokter Gigi & - & & 0,328 & 0,127 \\
Profesi Ners & - & - & & $0,001 *$ \\
Profesi Apoteker & - & - & - &
\end{tabular}
Uji statistik menggunakan one way ANOVA dan Post Hoc Tukey

* terdapat perbedaan signifikan. Nilai $\mathrm{p}<0,05$

Tabel 6 Persepsi Mahasiswa Rumpun Ilmu Kesehatan Unpad pada Setiap Komponen IPE

\begin{tabular}{|c|c|c|c|c|c|c|c|c|c|}
\hline \multirow[t]{3}{*}{ Program Studi } & \multicolumn{9}{|c|}{ Komponen IPE } \\
\hline & \multicolumn{3}{|c|}{ Kompetensi dan otonomi } & \multicolumn{3}{|c|}{$\begin{array}{c}\text { Kebutuhan yang dirasakan untuk } \\
\text { kerjasama profesional }\end{array}$} & \multicolumn{3}{|c|}{ Persepsi kerjasama Aktual } \\
\hline & Baik & $\underset{\text { baik }}{\text { C u k u p }}$ & $\underset{\text { baik }}{\text { Kurang }}$ & Baik & $\underset{\text { baik }}{\text { C u u p }}$ & $\underset{\text { baik }}{\text { Kurang }}$ & Baik & $\underset{\text { baik }}{\text { C u k u p }}$ & $\underset{\text { baik }}{\text { K u r a n g }}$ \\
\hline Kedokteran & $\begin{array}{l}28 \\
(100 \%)\end{array}$ & $\begin{array}{l}0 \\
(0 \%)\end{array}$ & $0(0 \%)$ & $\begin{array}{l}27 \\
(96,4 \%)\end{array}$ & $\begin{array}{l}1 \\
(3,6 \%)\end{array}$ & $0(0 \%)$ & $\begin{array}{l}27 \\
(96,4 \%)\end{array}$ & $\begin{array}{l}1 \\
(3,6 \%)\end{array}$ & $0(0 \%)$ \\
\hline $\begin{array}{l}\text { Pendidikan } \\
\text { Kedokteran } \\
\text { Gigi }\end{array}$ & $\begin{array}{l}27 \\
(96,4 \%)\end{array}$ & $\begin{array}{l}1 \\
(3,6 \%)\end{array}$ & $0(0 \%)$ & $\begin{array}{l}22 \\
(78,6 \%)\end{array}$ & $5(17,8 \%)$ & $1(3,6 \%)$ & $\begin{array}{l}28 \\
(100 \%)\end{array}$ & $\begin{array}{l}0 \\
(0 \%)\end{array}$ & $0(0 \%)$ \\
\hline Keperawatan & $\begin{array}{l}28 \\
(100 \%)\end{array}$ & $\begin{array}{l}0 \\
(0 \%)\end{array}$ & $0(0 \%)$ & $\begin{array}{l}25 \\
(89,2 \%)\end{array}$ & $3(10,8 \%)$ & $0(0 \%)$ & $\begin{array}{l}28 \\
(100 \%)\end{array}$ & $\begin{array}{l}0 \\
(0 \%)\end{array}$ & $0(0 \%)$ \\
\hline Farmasi & $\begin{array}{l}27 \\
(96,4 \%)\end{array}$ & $\begin{array}{l}1 \\
(3,6 \%)\end{array}$ & $0(0 \%)$ & $\begin{array}{l}24 \\
(85,7 \%)\end{array}$ & $4(14,3 \%)$ & $0(0 \%)$ & $\begin{array}{l}28 \\
(100 \%)\end{array}$ & $\begin{array}{l}0 \\
(0 \%)\end{array}$ & $0(0 \%)$ \\
\hline $\begin{array}{l}\text { Diploma } \\
\text { Kebidanan }\end{array}$ & $\begin{array}{l}28 \\
(100 \%)\end{array}$ & $\begin{array}{l}0 \\
(0 \%)\end{array}$ & $0(0 \%)$ & $\begin{array}{l}25 \\
(89,2 \%)\end{array}$ & $3(10,8 \%)$ & $0(0 \%)$ & $\begin{array}{l}28 \\
(100 \%)\end{array}$ & $\begin{array}{l}0 \\
(0 \%)\end{array}$ & $0(0 \%)$ \\
\hline $\begin{array}{l}\text { Profesi } \\
\text { Dokter }\end{array}$ & $\begin{array}{l}27 \\
(96,4 \%)\end{array}$ & $\begin{array}{l}1 \\
(3,6 \%)\end{array}$ & $0(0 \%)$ & $\begin{array}{l}27 \\
(96,4 \%)\end{array}$ & $\begin{array}{l}1 \\
(3,6 \%)\end{array}$ & $0(0 \%)$ & $\begin{array}{l}27 \\
(96,4 \%)\end{array}$ & $\begin{array}{l}1 \\
(3,6 \%)\end{array}$ & $0(0 \%)$ \\
\hline $\begin{array}{l}\text { Profesi } \\
\text { Dokter Gigi }\end{array}$ & $\begin{array}{l}27 \\
(96,4 \%)\end{array}$ & $\begin{array}{l}1 \\
(3,6 \%)\end{array}$ & $0(0 \%)$ & $\begin{array}{l}27 \\
(96,4 \%)\end{array}$ & $\begin{array}{l}1 \\
(3,6 \%)\end{array}$ & $0(0 \%)$ & $\begin{array}{l}28 \\
(100 \%)\end{array}$ & $\begin{array}{l}0 \\
(0 \%)\end{array}$ & $0(0 \%)$ \\
\hline Profesi Ners & $\begin{array}{l}25 \\
(89,3 \%)\end{array}$ & $\begin{array}{l}3 \\
(10,7 \%)\end{array}$ & $0(0 \%)$ & $\begin{array}{l}15 \\
(53,6 \%)\end{array}$ & $13(46,4 \%)$ & $0(0 \%)$ & $\begin{array}{l}27 \\
(96,4 \%)\end{array}$ & $\begin{array}{l}1 \\
(3,6 \%)\end{array}$ & $0(0 \%)$ \\
\hline $\begin{array}{l}\text { Profesi } \\
\text { Apoteker }\end{array}$ & $\begin{array}{l}27 \\
(96,6 \%)\end{array}$ & $\begin{array}{l}1 \\
(3,6 \%)\end{array}$ & $0(0 \%)$ & $\begin{array}{l}27 \\
(96,4 \%)\end{array}$ & $\begin{array}{l}1 \\
(3,6 \%)\end{array}$ & $0(0 \%)$ & $\begin{array}{l}28 \\
(100 \%)\end{array}$ & $\begin{array}{l}0 \\
(0 \%)\end{array}$ & $0(0 \%)$ \\
\hline Total & $\begin{array}{l}244 \\
(96,8 \%)\end{array}$ & $\begin{array}{l}8 \\
(3,2 \%)\end{array}$ & $0(0 \%)$ & $\begin{array}{l}219 \\
(86,9 \%)\end{array}$ & $32(12,7 \%)$ & $1(0,4 \%)$ & $\begin{array}{l}249 \\
(98,8 \%)\end{array}$ & $\begin{array}{l}3 \\
(1,2 \%)\end{array}$ & $0(0) \%$ \\
\hline
\end{tabular}


pada program studi profesi, terdapat $4,5 \%$ responden yang memiliki persepsi cukup baik

Penelitian ini sejalan dengan penelitian yang dilakukan di UMY untuk menilai persepsi mahasiswa Fakultas Kedokteran dan Ilmu Kesehatan tahap profesi terhadap IPE. Pada penelitian tersebut didapatkan bahwa persepsi dari masing-masing program studi termasuk dalam kategori baik dengan skor dari Kedokteran Umum (78,3\%), Kedokteran Gigi (78,3\%), Ilmu Keperawatan (81\%), dan Farmasi $(79,7 \%))^{10}$

Hasil ini juga sesuai dengan penelitian yang dilakukan oleh A'la dan Fauziah pada tahun 2010 kepada mahasiswa Fakultas Kedokteran UGM tentang persepsi dan kesiapan terhadap IPE. Didapatkan bahwa 92,8\% mahasiswa program studi sarjana memiliki kesiapan yang baik terhadap IPE dan 86,8\% mahasiswa memiliki persepsi baik terhadap IPE. Pada program studi profesi, sebanyak $88 \%$ mahasiswa menunjukkan tingkat kesiapan yang baik terhadap IPE dan $83,5 \%$ responden memiliki persepsi baik terhadap IPE. ${ }^{15}$

Mahasiswa program studi rumpun ilmu kesehatan di Unpad, UMY, dan UGM memiliki persepsi baik terhadap IPE. Akan tetapi, terlihat bahwa jumlah mahasiswa program studi sarjana yang memiliki persepsi baik lebih banyak dibandingkan dengan mahasiswa program studi profesi. Hal tersebut dapat disebabkan karena program pendidikan yang dilaksanakan berbeda.

Pada program studi sarjana dan diploma, mahasiswa mendapatkan paparan dan pengenalan terhadap IPC dalam bentuk intrakurikulum. Mahasiswa sudah dikenalkan dengan IPC meskipun belum dalam bentuk IPE yang seharusnya. Di Program Studi Kedokteran dan Diploma Kebidanan, IPE dimasukkan ke dalam Bioethics and Humaniora Programme (BHP) dan diberikan dengan metode mini lecture. Begitu juga pada program studi sarjana yang lain. Pada program studi profesi, mahasiswa tidak mendapatkan materi pembelajaran tentang IPE, tetapi langsung bekerjasama dengan profesi kesehatan lain. Hal ini menyebabkan lebih banyak mahasiswa program studi sarjana yang memiliki persepsi baik terhadap IPE dibandingkan dengan mahasiswa program studi profesi. Hal ini sesuai dengan penelitian yang dilakukan di Kanada yang menyatakan bahwa IPE yang dilakukan secara teori ataupun praktik dapat memberikan perubahan positif yang signifikan terhadap persepsi mahasiswa rumpun ilmu kesehatan terhadap profesi kesehatan. ${ }^{12}$

Pada komponen "kompetensi dan otonomi" serta komponen "persepsi kerjasama Aktual", $96,8 \%$ dan $98,8 \%$ responden memiliki persepsi yang baik. Hanya 3,2\% responden pada komponen "kompetensi dan otonomi" dan 1,2\% responden pada komponen "persepsi kerjasama dan pembagian sumber daya intra dan inter profesi" yang memiliki persepsi cukup baik. Hal tersebut menandakan bahwa responden sudah lebih memahami mengenai kompetensi dan otonomi profesinya masing-masing serta konsep kerjasama dan pembagian sumber daya, baik intra maupun inter profesi.

Bila melihat komponen "Kebutuhan yang dirasakan untuk kerjasama profesional", 12,7\% responden memiliki persepsi cukup baik dan 0,4\% responden memiliki persepsi kurang baik. Jumlah responden yang memiliki persepsi cukup baik terbagi rata antara program studi sarjana $(6,35 \%)$ dan program studi profesi $(6,35 \%)$. Pada Program Studi Pendidikan Kedokteran Gigi, terdapat responden yang memiliki persepsi kurang baik $(0,4 \%)$. Pada komponen ini, cukup banyak responden yang memiliki persepsi cukup baik dan ada yang kurang baik. Responden yang memiliki persepsi kurang baik berusia 20 tahun, berjenis kelamin perempuan, dan pendidikan terakhir berasal dari SMA. Karakteristik yang dimiliki oleh responden ini tidak jauh berbeda dengan responden lainnya.

Jumlah responden yang memiliki persepsi cukup baik dan kurang baik pada komponen "Kebutuhan yang dirasakan untuk kerjasama profesional" lebih banyak dibandingkan dengan komponen IPE lainnya. Hal ini menunjukkan bahwa responden sudah cukup memahami mengenai kompetensi, otonomi, persepsi kerjasama, dan pembagian sumber daya intra dan inter profesi. Akan tetapi, kebutuhan yang dirasakan untuk kerjasama profesional masih kurang. Berdasarkan penelitian yang dilakukan kepada mahasiswa tahap profesi FKIK UMY, komponen pemahaman terhadap profesi lain memiliki rerata paling rendah karena kurangnya interaksi dan komunikasi antar profesi. ${ }^{10}$

Dari kedua penelitian, terlihat bahwa pemahaman mahasiswa tentang profesi tenaga kesehatan lain dan perlunya bekerjasama belum cukup memadai karena kurangnya interaksi dan komunikasi antar profesi. Kemampuan komunikasi yang diajarkan kepada mahasiswa hanya terfokus pada interaksi dengan pasien dan keluarganya dari sudut pandang profesinya masing-masing, bukan komunikasi antar profesi. Sudut pandang spesifik dari masing-masing profesi hanya menyiapkan individu untuk bekerja dalam lingkungan seprofesinya, akan tetapi tidak untuk berkomunikasi dengan individu dari profesi lain. ${ }^{16}$

Persepsi cukup baik dan kurang baik yang muncul pada komponen "Kebutuhan yang dirasakan untuk kerjasama profesional" ini paling 
banyak terlihat pada Ners, kemudian pada seluruh program studi sarjana. Padahal, kerjasama antar tenaga kesehatan sangat diperlukan. Kurangnya rasa kebutuhan untuk kerjasama profesional ini mungkin disebabkan karena belum adanya paparan mengenai peran dari masing-masing profesi tenaga kesehatan, terutama pada program studi sarjana. Hal ini mengakibatkan responden hanya memahami mengenai peran dari profesi tenaga kesehatannya masing-masing. Pemahaman yang kurang baik akan menyebabkan kompetensi yang tumpang tindih dan batasan peran yang tidak jelas. ${ }^{16}$ Selama ini, mahasiswa program studi rumpun ilmu kesehatan Unpad hanya mempelajari mengenai profesi tenaga kesehatannya masing-masing tanpa mengetahui batasan peran dengan profesi tenaga kesehatan lainnya.

Masalah ini paling terlihat pada program studi profesi yang memberikan persepsi cukup baik lebih banyak dibandingkan dengan program studi sarjana dan diploma. Faktor yang memengaruhi hal ini mungkin dikarenakan proses pendidikan yang tidak mendorong mahasiswa untuk saling mengenal dan bekerja sama. Bahkan, mahasiswa program studi profesi yang sedang menjalani fase klinik di rumah sakit sangat jarang bekerja sama dengan profesi lain. ${ }^{16}$ Padahal, kompetensi untuk bekerja sama intra dan interprofesional dalam tim pelayanan kesehatan terdapat dalam Standar Kompetensi Dokter Indonesia, Standar Kompetensi Bidan Indonesia, dan standar kompetensi tenaga kesehatan lainnya. Profesi tenaga kesehatan harus bekerjasama dalam menangani pasien sehingga dibutuhkan pemahaman tentang kerjasama yang baik antar profesi tenaga kesehatan.

Oleh karena itu, perlu diadakan IPE sebagai sarana pembelajaran bersama antar program studi rumpun ilmu kesehatan di Unpad agar mahasiswa program studi rumpun ilmu kesehatan dapat lebih memahami mengenai profesi tenaga kesehatan lainnya dan kerjasama antar profesi tenaga kesehatan. Pemahaman yang lebih baik diharapkan dapat meningkatkan IPC sehingga pelayanan kesehatan yang diberikan menjadi lebih baik. Dengan persepsi yang baik dari mahasiswa rumpun ilmu kesehatan, penerapan IPE di Unpad akan lebih mudah.

Terdapat keterbatasan dalam penelitian ini. Pertama, penelitian ini hanya menggunakan data dari kuesioner yang diisi secara langsung oleh responden sehingga tidak dapat divalidasi kebenarannya. Selain itu, penelitian ini tidak melakukan observasi langsung dalam penyelenggaraan pendidikan di masing-masing program studi. Pada penelitian ini faktorfaktor yang mungkin memengaruhi IPE belum dihilangkan, seperti perbedaan lingkungan pengajaran, kesiapan, dan proses sosialisasi IPE di masing-masing program studi. ${ }^{17}$

Untuk penelitian berikutnya, lebih baik diadakan observasi langsung terhadap metode pengenalan IPC di masing-masing program studi sebagai bahan evaluasi awal untuk pelaksanaan IPE. Perbedaan kurikulum pembelajaran antar program studi juga perlu diteliti lebih jauh.

\section{Daftar Pustaka}

1 Perwitasari DA, Abror J, Wahyuningsih I. Medication Errors in Outpatients of a Government Hospital in Yogyakarta Indonesia. 2010;1(1):8-10.

2. Easton K, Morgan T WM. Medication safety in the community: a review of the literature. Natl Prescr Serv. 2009;

3. Susilaningsih FS. Nurse-Physician Collaborative Practice in Interdisciplinary Model of Patient Care. Jurnal Manajemen Pelayanan Kesehatan. 2011;14(02).

4. Orchard CA, Curran V, Kabene S. Creating a Culture for Interdisciplinary Collaborative Professional Practice. 2005;(2000):1-13.

5. Kenaszchuk C. An inventory of quantitative tools measuring interprofessional education and collaborative practice outcomes. Journal of Interprofessional Care. 2013 Jan $1 ; 27(1): 101-$.

6. WHO. Transforming and Scaling up Health Professional's Education and Training. Geneva: World Health Organization. 2013.

7. Thannhauser J, Russell-Mayhew S, Scott C. Measures of interprofessional education and collaboration. $\mathrm{J}$ Interprof Care. 2010;24(4):336-49.

8. Buring SM, Bhushan A, Broeseker A, Conway S, Duncan-Hewitt W, Hansen L, dkk. Interprofessional education: Definitions, student competencies, and guidelines for implementation. Am J Pharm Educ. 2009;73(4).

9. Thistlethwaite J. Interprofessional education: A review of context, learning and the research agenda. Med Educ. 2012;46(1):58-70.

10. Sundari S. Perbedaan Persepsi Mahasiswa Tahap Profesi di FKIK UMY tentang Interprofessional Education di Asri Medical Center Yogyakarta. Med Educ. 2013;

11. Kesuma D. Persepsi Mahasiswa Fakultas Kedokteran dan Ilmu Kesehatan UIN Syarif Hidayatullah Jakarta terhadap Interprofessional Education. 2015.

12. Ateah CA, Snow W, Wener P, MacDonald L, Metge C, Davis P, Fricke M, Ludwig 
S, Anderson J. Stereotyping as a barrier to collaboration: Does interprofessional education make a difference?. Nurse education today. $2011 \mathrm{Feb} 28 ; 31(2): 208-13$.

13. Faul F, Erdfelder E, Lang A-GG, Buchner A, Kiel C. G*Power3: A Flexible Statistical Power Analysis Program for the Social, Behavioral, and Biomedical Sciences. Behav Res Methods [Internet]. 2007;39(2):175-91. Available from: http://www.psycho.uniduesseldorf.de/abteilungen/aap/gpower3/

14. Faul F, Erdfelder E, Buchner A, Lang A-G. Statistical power analyses using $G^{*}$ Power 3.1: tests for correlation and regression analyses. Behav Res Methods [Internet]. 2009;41(4):1149-60. Available from: http:// www.ncbi.nlm.nih.gov/pubmed/19897823

15. McFadyen a K, Maclaren WM, Webster VS.
The Interdisciplinary Education Perception Scale (IEPS): an alternative remodelled subscale structure and its reliability. J Interprof Care. 2007;21(4):433-43.

16. Azwar S. Penyusunan Skala Psikologi. Yogyakarta: Pustaka Pelajar. 2005;187-96.

17. HPEQ-Project. Persepsi dan Kesiapan Mahasiswa \& Dosen Profesi Kesehatan Terhadap Model Pembelajaran Pendidikan Interprofesi. 2011;

18. Hall P. Interprofessional teamwork: professional cultures as barriers. J Interprof Care. 2005;19(1):188-96.

19. Oandasan I, Reeves S. Key elements of interprofessional education. Part 2: factors, processes and outcomes. J Interprof Care. 2005;19 Suppl 1(May):39-48. 